\title{
Routine endoscopic ultrasound in moderate and indeterminate risk patients of suspected choledocholithiasis to avoid unwarranted ERCP: A prospective randomized blinded study
}

\author{
Supriyo Ghatak $^{1} \cdot$ Sumit Gulati $^{1}$
}

Published online: 26 July 2016

(C) Indian Society of Gastroenterology 2016

We read with great interest the article "Routine endoscopic ultrasound in moderate and indeterminate risk patients of suspected choledocholithiasis to avoid unwarranted ERCP: a prospective randomized blinded study" by Sharma et al. [1].

While the study setting has been mentioned as a tertiary care hospital, it appears that three hospitals were involved, not one. Patients were randomized into two groups but the exact method of randomization is not mentioned. Our primary concern about this study was ethical. In group A, all patients underwent ERCP irrespective of the EUS findings. Authors quoted a procedure-related morbidity for ERCP ranging from $5 \%$ to $6 \%$ and mortality of $0.07 \%$ to $0.1 \%$. Was it ethically justifiable to submit all these patients to ERCP especially in those where there were no stones in EUS? Similarly, how justified was it to follow up patients in group B with EUS twice without any clinical or biochemical suspicion of retained bile duct stone? Finally, we were surprised to see that not a single patient was excluded after assessment for eligibility by the criterion "presence of CBD stones in transabdominal ultrasound".

\section{References}

1. Sharma R, Menachery J, Choudhary NS, et al. Routine endoscopic ultrasound in moderate and indeterminate risk patients of suspected choledocholithiasis to avoid unwarranted ERCP: a prospective randomized blinded study. Indian J Gastroenterol. 2015;34:300-4.
Supriyo Ghatak

drsupriyo@yahoo.co.in

1 Department of Surgical Gastroenterology, Calcutta Medical Research Institute, 7/2 Diamond Harbour Road, Kolkata 700 027, India 